\title{
Renewing Theories, Methods and Design Practices: Challenges for Architectural Education
}

\author{
Yandi Andri Yatmo ${ }^{1, *}$ \\ ${ }^{1}$ Department of Architecture, Faculty of Engineering, Universitas Indonesia, Indonesia
}

\begin{abstract}
Architectural education should promote the advancement of knowledge that is necessary as the basis for the development of excellent design practice. Architectural education needs to respond appropriately to the current issues in the society. To find its way into the society in an appropriate way, architecture needs to be liquid. The ability to address the liquidity of architecture requires educational approach that promotes the ability to work with a range of design methods and approaches. There are several principles that become the basis for developing architectural education that could strengthen its position within the society: to promote knowledge-based design practice, to embrace variety of design methods and approaches; to keep a balance between design knowledge and design skills; while at the same time to aim for mastery and excellence in design. These principles should be the basis for defining and developing the curriculum and the process of design learning architectural education. Then the main challenge is on our willingness to be liquid in developing architectural education, which needs continuous renewal and update to respond to the changing context of knowledge, technology and society.
\end{abstract}

Keywords: design methods, design knowledge, liquid, society, education

\section{Introduction: Why Do We Need to Renew?}

As a discipline that addresses the inhabitation of human, architecture is very closely related to the society. The practice of design in architecture needs to respond directly to the needs and issues in the society. Design can be defined as "the human capacity to shape and make our environment in ways without precedent in nature, to serve our needs and give meaning to our lives" (Heskett, 2002, p. 5). This definition at least implies two things: the importance of innovation to find something new with no precedent, and the importance of design practice to become meaningful for the life of the society.

The demand to serve the society has inevitable lead to the challenges of architectural education to offer sufficient knowledge and skills for its students and graduates to be ready for those meaningful, innovative design practice. Architectural education sits between two requirements: to contribute to the society through appropriate design practice, and to promote excellence in design practice that could break the boundaries of innovation in architectural methods and approaches. Keeping the balance between these two requirements become a challenge. It is imperative that we consider architectural education institutions not merely as factories to produce the graduates to supply the demands of the society. Architectural education should always be the place where knowledge is cultivated, and where new things are invented.
To address this challenge, renewing architectural education becomes critical. Architectural education should become the generator for promoting renewal of theories, methods and practice, in order to achieve advancement in architectural design practice. This paper proposes five main principles as the basis for developing architectural education in responding to these challenges.

\section{Architecture Practice Must be Liquid}

The first principle suggests that we need to understand that architecture needs to be liquid so that it becomes appropriate for the society where it exists. In physics, the liquid characteristic refers to the ability of a substance to change and adjust to its container. Architecture could become liquid when it emerges as the manifestation of the design process that responds appropriately to various aspects of socio-culture, everydayness, locality and agency of the society. Architecture becomes liquid since it depends on many things that are located external of the architecture itself (Till, 2009).

The idea of liquid architecture also contradicts the common understanding of architecture as fixed and complete. Architecture should be liquid because it may evolve as a process that does not always match with initial drawings of the architect; it evolves as a process that provides opportunities for change and modification that might be necessary so that it becomes more meaningful for the society. Liquid architecture is the 
opposite of the complete architecture. Architecture that is incomplete may give space for the society to complete it; it becomes as space for the society to leave traces, as a way to mark their existence as an integral part of the architecture.

Liquid architecture requires architects to understand their appropriate position in the context where they work. It requires the ability to understand the deep structure of the context, to understand the everyday of the society, to develop appropriate strategies for intervention, and to be ready to adapt and to adjust. Because architecture should be liquid, therefore it is necessary for the practice of architecture to develop appropriate design methods that could fit properly with various situation of the society. As a consequence, it is imperative that architectural education promote the ability to maneuver in between such liquid characteristics of architecture, through the renewal of its curriculum and learning approaches.

\section{Architectural Education Should Promote Knowledge-based Design Practice}

The ability to respond appropriately with the design contexts and issues requires more than just the acquisition of the design skills. It is necessary for the architectural design practice to be based strongly on knowledge. There is an important statement from Vitruvius that delivers an important message for all teachers and learners of architecture.

"Architects who have aimed at acquiring manual skill without scholarship have never been able to reach a position of authority to correspond to their pains, while those who relied only upon theories and scholarship were obviously hunting the shadow, not the substance. But those who have a thorough knowledge of both, like men armed at all points, have the sooner attained their object and carried authority with them" (Vitruvius, 1960)

Vitruvius clearly pointed out the importance of theory and scholarship as a basis for the practice of architecture. Theory has a critical role as "an intellectual tool" for the development of architecture as a discipline (Plowright, 2014, p. 58). It becomes necessary to find the scholarship of design and use it as the basis of our teaching and practice in architecture. "since knowledge is defined within a discipline, rather than externally, scholarship is also defined by discipline" (Powers, 2007, p. 18).

Without the development of knowledge, it is unlikely that the practice and method of architecture could be developed; "the advancement of architecture is inextricably linked to the acquirement of knowledge" (Till, 2009, p. 2). There has been a challenge on how theory could be used in design practice, in particular to become the generator of architectural design (Plowright, 2014). Theories are taught in most schools of architecture, however, the extent to which we could directly relate the theories taught in theory classes and the design practice in the studio remains a challenge.
So the second principle I propose here is that architectural education should promote knowledge-based design practice. The design learning process needs to prioritize thinking and inquiry throughout the process of designing. This will ensure that the process of design learning becomes the process of developing knowledge and generating ideas and not just the process of manual crafting and generating product. Architectural education institution should become the place where thinking is nurtured and developed.

\section{Architectural Education Should Embrace Variety of Design Methods and Approaches}

The first principle stands on the belief that architecture needs to be liquid so that it could address the context of the society more appropriately. The second principle emphasizes on the challenge of architectural education to teach design knowledge as the basis for design practice. Further implications of these two is the needs for architectural education to open opportunities to learn variety of design methods, in order to equip the students with the ability to manoeuvre in between the different contexts with strong basis of knowledge.

The scope of architectural education should cover a wide range of design methods and approaches and celebrate the strength of each. The objectives of architectural design studios should not be to promote mastery in certain method only, as this may limit the ability of the graduates to respond to the complexity of design issues and problems in the society.

We can take an analogy of learning to swim for learning to design. To learn to swim, students need to be introduced to and required to practice a variety of swimming stroke. The acquisition of different strokes become more important then the ability to swim the furthest distance with only one particular stroke. Each swimming stroke offer different strength, and each needs to be used in different terrain. Particular stroke might give benefit in reaching particular distance with speed, while another might be better to survive in a long distance travel. This situation is similar to design methods; each method has its own strong point when applied into different design contexts. Exposing students to different design methods and approaches could prepare them to respond to different contexts in reality. The development of the students' ability to manoeuvre in different terrains of design contexts become the main challenge for architectural education.

This analogy is particularly relevant for undergraduate education where the students should acquire holistic understanding on architectural design and not just specializing on particular method or approach only. To expose students with a variety of design methods and approaches, the curriculum of architecture should define different kinds of design knowledge for each stage of design studio. The contents of design studios at each level should not be based on types or project complexity as often developed in the curriculum in many architecture schools. It becomes 
necessary to define clearly the types of knowledge to be delivered and the main design approached to be acquired in each studio.

\section{Architectural Education Should Keep the Balance Between Knowledge and Skills}

While knowledge should become the heart of design learning, this does not necessarily mean the ignorance of relevant skills in design. As stated by Vitruvius, the acquisition of knowledge only will not result in completeness of being an architect, and so is the acquisition of skills only. Therefore, architectural education should keep the correct balance between knowledge and skills.

The types of skills to be trained in architectural education cannot be separated from the knowledge developed. This is what I call knowledge-based skills that is the skills that are developed in parallel with the development of knowledge. Skills of representation need to be developed in relation to the ideas, the thinking, the methods and approaches that are developed in the design process. Each design method and approach may require different techniques of representation and thus require different skills. Particular design methods may require certain technical skills and acquisition of certain technical tools. Therefore, the content of knowledge in each design studio needs to be accompanied with relevant skills that enable the students to exercise particular design method and approach more comprehensively.

Other sets of skills that need to be developed in architectural education are the skills that are required for being liquid in the process of developing architectural ideas. It is important that the students are equipped with a set of skills that enable them to manoeuvre easily within the society - to listen, to adjust, to adapt, and to go with the flow, and to design in between this process. These skills might be in contrast with the belief that the education should allow the students to speak, to be confident, to defend the idea, and to win the argument, as the part of the studio culture developed in most architecture schools. It is time to redirect the studio culture into the constructive environment where the skills for being liquid are nurtured, to enable the students to adapt easily within the society and to be flexible in facing different situations.

\section{Architectural Education Should Aim for Mastery and Excellence}

Education at postgraduate level requires different approach. While the education at undergraduate needs to expose students with different knowledge, skills, methods and approaches, these are mainly at the basic level that opens opportunities for improvement. Education at postgraduate level should aim for mastery and excellence in design practice. The learning at postgraduate level needs to promote the ability to determine the position among possible design approaches.

Many architecture schools mixed up the mastery in design with the mastery in problem solving, or mastery in technical skills. This is an incorrect path of architectural education, as mastery should be developed as the mastery in the scholarship of design. Mastery and excellence at postgraduate level needs to be developed through the advancement of knowledge, the depth of the inquiry, the experiment in design methods and the invention in the modes of representation. All these become important ingredients to achieve the mastery and excellence in design practice that should be promoted in architectural education.

Research by design (Fraser, 2013) becomes a key aspect in the design education particularly at postgraduate level. It promotes the ability to see design as a process of inquiry, where new design knowledge may emerge and new design method may develop. Supervising the research by design is not an easy task for architectural schools, since there are a wide range of possibilities in the process of inquiry and the process of design. Nevertheless, research by design becomes an appropriate way to promote mastery and excellence in design practice.

\section{Towards Renewal of Architectural}

\section{Education}

The five principles that I propose here has come out of my experience in innovating with different methods and approaches of design studio learning. These are the principles that I believe should be the basis for developing curriculum in architectural school in order to promote the ability to develop design practice that are both excellent and responsive. There are, however, some consequences that will come with these principles. The principles will require the renewal of curriculum, to distribute the content of design knowledge more appropriately, to achieve the balance between knowledge and skills, and to nurture the culture of inquiry. Others challenges may include the necessary updating of the teachers, promoting collaboration between different areas of architectural learning, and providing the infrastructure to support the process. However, the main challenge is on the willingness to be liquid in developing architectural education, which needs continuous renewal and update to respond to the changing context of knowledge, technology and society.

\section{References}

Fraser, M. (Ed.) (2013). Design Research in Architecture: An Overview. London: Routledge.

Heskett, J. (2002). Design: A Very Short Introduction. Oxford: Oxford University Press.

Plowright, P. (2014). Revealing Architectural Design: Methods, Frameworks and Tools. London: Routledge. 
Powers, M. (2007). Toward a Discipline Dependent Scholarship. Journal of Architectural Education, 61, 15-18.

Till, J. (2009). Architecture Depends. Cambridge, MA.: MIT Press.

Vitruvius (1960). The Ten Books on Architecture. Trans. Morris Hicky Morgan. New York: Dover Publications. 